\title{
CDISC Protocol Entities Study Contact Information Attribute Terminology
}

National Cancer Institute

\section{Source}

National Cancer Institute. CDISC Protocol Entities Study Contact Information Attribute

Terminology. NCl Thesaurus. Code C154682.

Terminology associated with the protocol entity study contact information attribute codelist of the Clinical Data Interchange Standards Consortium (CDISC). 